\title{
'Chameleonic' Serological Findings Leading to Life-Threatening Hemolytic Transfusion Reactions
}

\author{
Ariane Sümnig ${ }^{a} \quad$ Beate Mayer $^{\mathrm{b}} \quad$ Volker Kiefel $^{\mathrm{c}} \quad$ Andreas Greinacher $^{\mathrm{a}} \quad$ Abdulgabar Salama $^{\mathrm{b}}$ \\ ${ }^{a}$ Department of Immunology and Transfusion Medicine, Universitätsmedizin Greifswald, Greifswald, Germany; \\ b Institute for Transfusion Medicine, Charité - Universitätsmedizin Berlin, Berlin, Germany; \\ cInstitute for Transfusion Medicine, Universitätsmedizin Rostock, Rostock, Germany
}

\section{Keywords}

Hemolytic anemia - Transfusion reaction - Auto-anti-D . $\mathrm{Rh}(\mathrm{D})$-blocked phenomenon - Antigen suppression

\section{Summary}

Background: The phenomena of co-incidence of transfusion-induced allo- and autoantibodies, blockage and/or loss of red blood cell (RBC) antigens are conspicuous and may result in confusion and misdiagnosis. Case Report: A 67-year-old female was transferred to the intensive care unit due to hemolysis which developed 2 days following transfusion of three $\mathrm{Rh}(\mathrm{D})$-negative RBC units in the presence of strongly reactive autoantibodies. Standard serological testing and genotyping were performed. Upon arrival, the patient was typed as Ccddee. Her hemolysis was decompensated, and an immediate blood transfusion was required. In addition, direct and indirect antiglobulin tests (DAT and IAT) as well as the eluate were strongly positive. Emergency transfusion of Rh(D)negative RBCs resulted in increased hemolysis and renal failure. An exhaustive testing revealed anti-D, anti-C, CCddee phenotype and CCD.ee genotype. Three units of cryopreserved CCddee RBCs were transfused, and the patient's condition immediately improved. The discrepancy between Rh-D phenotyping and genotyping was likely caused by masking of the D-epitopes by the autoantibodies. In fact, further enquiry revealed that the patient had been phenotyped as Rh(D)-positive 6 months ago and had been transfused at that time following hip surgery. Conclusion: The phenomena of transfusion-induced autoantibodies, masked alloantibodies, antigen blockage and/or loss are rare but important features which should be considered in patients presenting with autoimmune hemolytic anemia and/or hemolytic transfusion reactions.

(c) 2015 S. Karger GmbH, Freiburg

\section{Introduction}

In general, hemolytic transfusion reactions (HTRs) are well characterized by their occurrence in association with blood transfusion. Key serological findings are predominantly detectable alloantibodies in serum samples of affected patients and, to a variable extent, a positive direct antiglobulin test (DAT) occurring in association with or without clinical or laboratory signs of hemolysis (clinical HTR or serological HTR). In comparison, autoimmune hemolytic anemias (AIHA) are characterized by their clinical pictures, a positive DAT, and in cases of warm-type AIHA by autoantibodies, which are predominantly detectable on patients' red blood cells (RBCs) and to a lesser degree as free antibodies in the serum [1-3]. However, the results of serological findings in HTRs are variable and may result in confusion. Often they are dependent on numerous factors such as the causative antibodies, the amount of transfused RBCs, the time interval between the last transfusion and testing, and the methods applied for analysis. Here, we report on a patient with intriguing serological findings, which resulted in incompatible blood transfusions and life-threatening hemolysis.

\section{Material and Methods}

Indirect antiglobulin test (IAT) and DAT were performed using the standard gel technique (Bio-Rad, Cressier sur Morat, Switzerland). All anti-immunglobulin (Ig) reagents used were from commercial sources: anti-IgG, anti-IgA, anti-IgM (Bio-Rad Medical Diagnostics, Dreieich, Germany) and anti-C3d (Dako, Hamburg, Germany). Eluate from the patient's RBCs was prepared using the acid method (BAG, Lich, Germany). Serum and eluate IAT tests were performed using polyspecific Ig cards, and neutral gel cards were used for twostage enzyme technique (BioRad). For differentiation of Anti-c und Anti-D, rare RBCs (Rh null, CCddee) from in-house library were used. Auto anti-LW was considered, but LW-negative, D-positive and c-negative RBCs were not available for testing.

Blood group antigens for D, C, E, c, and e were determined by hemagglutination in gel cards using monoclonal reagents (BioRad) or by automated microplate technique (Galileo Immucor, Norcross, GA, USA). Genotyping for

\section{KARGER}

Fax +497614520714 (c) 2015 S. Karger GmbH, Freiburg

$1660-3796 / 15 / 0425-0340 \$ 39.50 / 0$ 


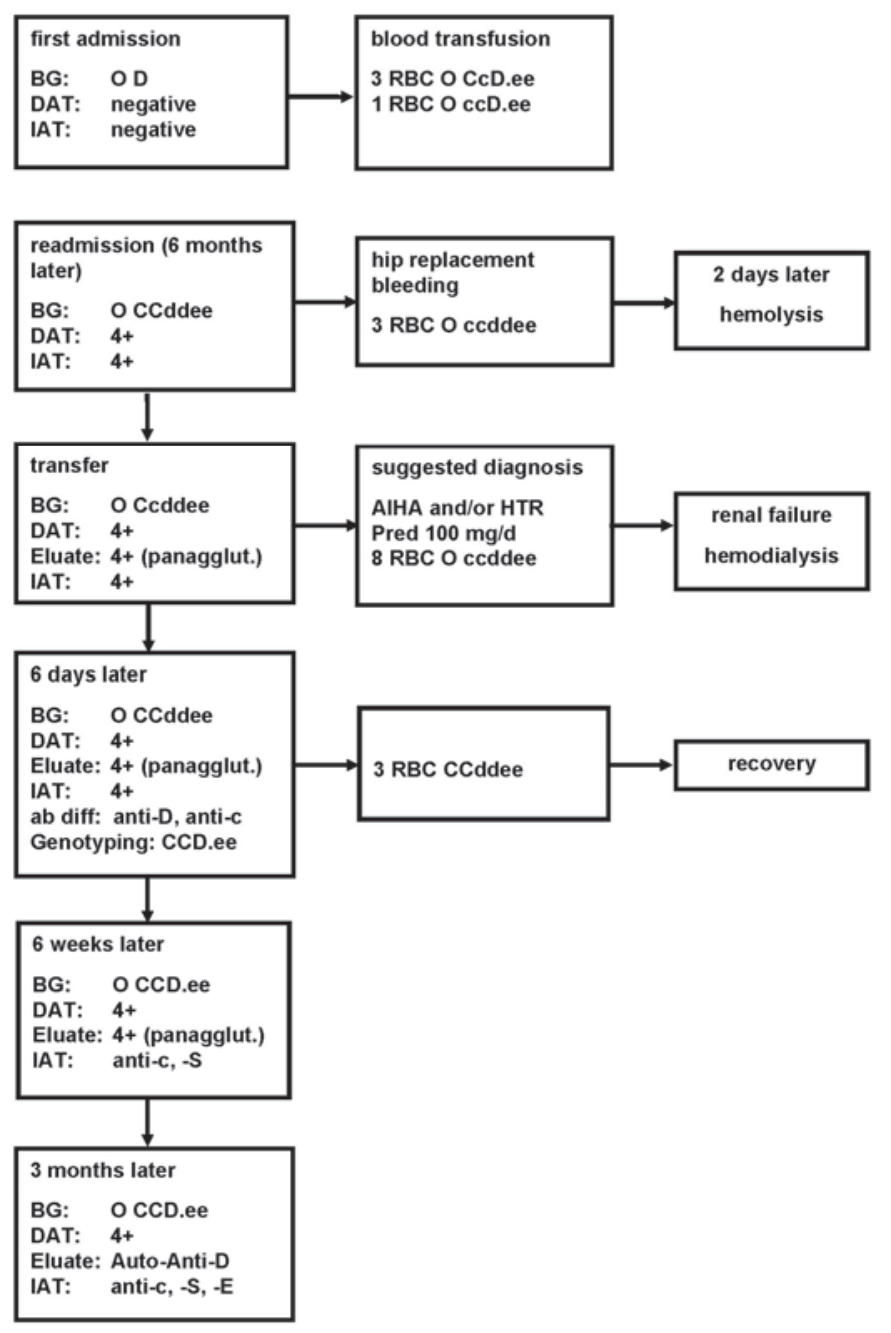

Fig. 1. Patient's course, serological findings, result of genotyping and treatment. BG = blood group; $4+=$ Degree of reactivity (very strong); panagglut. = panagglutinating antibody; $\mathrm{ab}$ diff = antibody differentiation; Pred = prednisolone.

RHD and RHCE was performed after DNA extraction using PCR-SSP (BAG and Inno-train, Kronberg, Germany, respectively) and exon sequencing of $R H D$ gene.

\section{Case Report}

A 67-year-old woman, with a history of hip surgery and blood transfusion (three O CcDee and one O ccDee) 6 months previously, was re-admitted to hospital for total hip replacement surgery (fig. 1). During this procedure, an urgent blood transfusion was required due to significant blood loss. Though the patient was typed as $\mathrm{O} R \mathrm{R}(\mathrm{D})$-positive prior to the first hip replacement, retyping revealed CCddee. However, the DAT and antibody screen test were strongly positive, leading to the assumption that a positive Coombs cross-match of RBCs, prepared for perisurgery blood demand, was related to a high-titer autoantibody. No signs of hemolysis were present, and three cross-match-positive $\mathrm{Rh}(\mathrm{D})$-negative (ccddee) RBC units were transfused during surgery. The patient developed a delayed hemolytic transfusion reaction 2 days posttransfusion and was transferred to the intensive care unit (ICU) at the university hospital. On arrival, hemolysis was decompensated (hemoglobin concentration $6.4 \mathrm{~g} / \mathrm{dl}$ (reference range 11.9-16.1 g/dl), lactate dehyrogenase 1,248 U/l (reference range $<250 \mathrm{U} / \mathrm{l}$ ) , haptoglobin $<0.08 \mathrm{~g} / \mathrm{l}$ (reference range $0.3-2.0 \mathrm{~g} / \mathrm{l}$ ), free hemoglobin in plasma $27 \mu \mathrm{mol} / \mathrm{l}$ (reference range $0-10 \mu \mathrm{mol} / \mathrm{l}$ ), creatinine 351 $\mu \mathrm{mol} / \mathrm{l}$ (reference range $42-80 \mu \mathrm{mol} / \mathrm{l}$ ) and indirect bilirubin $169.6 \mu \mathrm{mol} / \mathrm{l}$ (reference range $0-17 \mu \mathrm{mol} / \mathrm{l})$ ) requiring further emergency blood transfusions.

\section{Results}

Serological examination revealed blood group type O Ccddee, strong positive DAT (anti-IgG 4+ and anti-C3d 1+) and panagglutinating IAT using both serum and eluate samples. AIHA was suspected, and treatment with steroids ( $100 \mathrm{mg} /$ day prednisolone) commenced. The patient subsequently received 8 units of $\mathrm{O}$ $\mathrm{Rh}(\mathrm{D})$-negative RBCs over the span of 6 days. Clinical signs of acute hemolytic reactions, e.g. back pain, were not observed, probably due to persistent hemolysis and treatment with steroids. Hemolysis could not be halted, and the patient required hemodialysis due to renal failure. Subsequent examinations, including testing of rare $\mathrm{RBCs}$, revealed in parallel the phenotype CCddee, anti-D, anti-c, and genotype CCD.ee (including sequencing). Three units of cryopreserved CCddee RBCs were transfused; the patient's hemoglobin concentration increased from 4.5 to $6.7 \mathrm{~g} / \mathrm{dl}$ and hemolysis gradually abolished (fig. 2). Control testing following a time span of 6 weeks demonstrated phenotype O CCD.ee, anti-c, anti-S, strong positive DAT and panagglutinating eluate. Three months later, serological re-examination confirmed blood group $\mathrm{O}$ CCD.ee. In addition, anti-E was detectable in the patient's serum, and the DAT was strongly positive due to auto-anti-D (fig. 1).

\section{Discussion}

The patient described here demonstrates various intriguing serological findings, which resulted in confusion and HTR. The patient was admitted to the ICU, blood transfusion was urgently required, and no cross-match-compatible RBCs were available. At this time the true rhesus antigens were unknown due to prior transfusions, the true diagnosis was unclear, and blood samples for extensive testing were limited due to significant hypoxic anemia. In this scenario the risk of severe morbidity and a fatal outcome due to hypoxemia had to be balanced against the risk of incompatible blood transfusion. The DAT was strongly positive prior to the first perisurgical transfusion and the hemolytic attack. This led to the following considerations:

The patient may have AIHA of warm type, which exacerbated due to blood transfusion. Consequently a treatment with steroids was commenced.

The patient may have a HTR due to autoantibodies with a concomitant antibody directed against a high-frequency antigen. Ultimately, the causative antibodies were a combination of auto-anti- $\mathrm{D}$ and anti-c, which gave homogeneous reactions with all normal RBCs. This reaction pattern is usually typical for the presence of an antibody directed against a high-frequency antigen. In this case, incompatible transfusion would be acceptable in order to save the patient's life as long as the causative alloantibody could not be identified. 


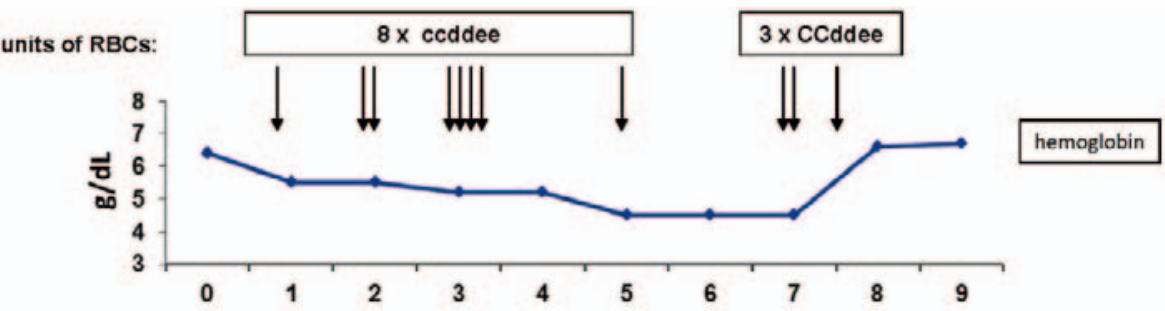

Fig. 2. Course of $\mathrm{RBC}$ transfusion, hemoglobin (reference range 11.9-16.1 g/dl), creatinine (reference range $42-80 \mu \mathrm{mol} / \mathrm{l}$ ), and bilirubin (reference range $0-17 \mu \mathrm{mol} / \mathrm{l})$.

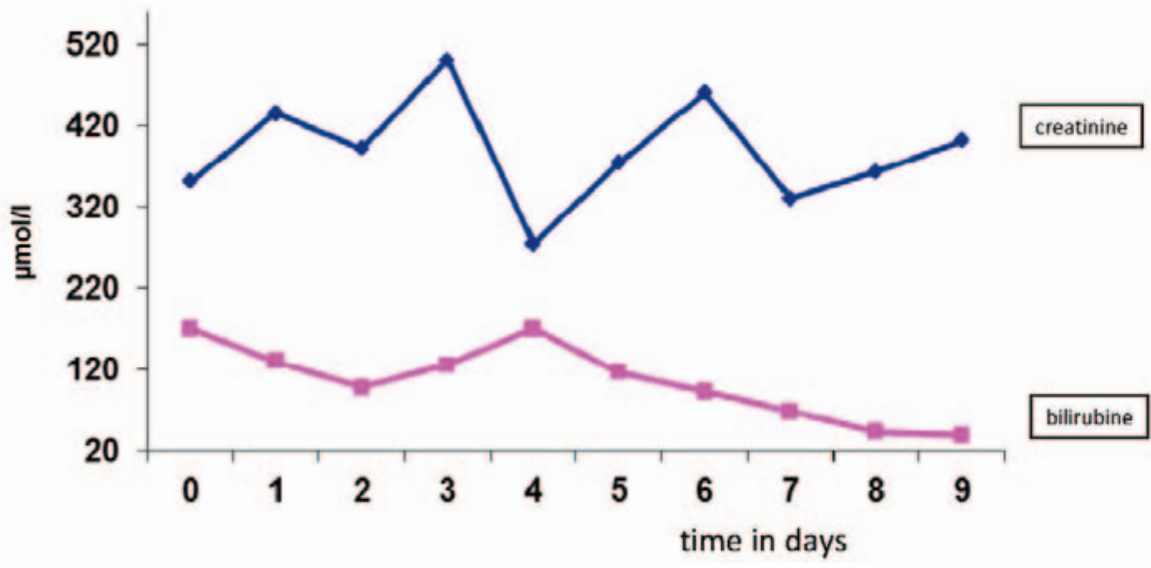

The patient must have developed a HTR due to masked alloantibodies. This scenario was surrounded by various interesting serological findings including the development of autoantibodies following blood transfusion, $\mathrm{Rh}(\mathrm{D})$ blocked phenomenon, masked anti-c, and false-positive c-phenotyping due to the transfused RBCs. All these phenomena are worth to be discussed further.

The occurrence of autoantibodies following blood transfusion has been described approximately 30 years ago [4]. Most intriguingly, these autoantibodies seem to persist for a long period of time without evidence of hemolysis. In the presented case, the most likely trigger for induction of autoantibodies was the blood transfusion during the first hip replacement surgery. Although the phenomenon of blood transfusion-induced autoantibodies has been supported by other groups $[5,6]$, it remains rather confusing in many cases.

While the presence of RBC alloantibodies in patients with AIHA is well known among transfusion laboratory personnel, the induction of autoantibodies by blood transfusion is less known. It has been shown that the co-incidence of alloantibodies and autoantibodies in 'true' AIHA is less common than that of autoantibodies and alloantibodies following hemolytic or non-hemolytic transfusion reactions $[7,8]$. This indicates, that the co-incidence of autoantibodies and alloantibodies reflect hemolytic or non-hemolytic transfusion reactions rather than AIHA.

The patient presented here appeared to had developed a potent auto-anti-D that resulted in the so-called blocked $\mathrm{Rh}(\mathrm{D})$ phenomenon. This phenomenon has been described in newborn hemolytic disease [9-11] and by the use of murine monoclonal antibodies [12-14]. To our knowledge, this is the first report describing this phenomenon in AIHA and serological transfusion reactions.

The question why transfusion-induced autoantibodies remain detectable for a long time and do not cause significant hemolysis is obscure.
A further potential scenario was that the patient had a variant $\mathrm{Rh}(\mathrm{D})$ antigen and had developed an alloantibody against unexpressed epitopes on autologous RBCs. This hypothesis was somewhat supported by the fact that isolated patients with $\mathrm{Rh}(\mathrm{D})$ variants may develop strong anti-D [15-17]. This hypothesis was later excluded by the results obtained from genotyping.

On admission to ICU, rhesus $\mathrm{c}$ antigen was detectable on circulating RBCs (fig. 1). This was likely caused by the c-positive RBCs transfused 2 days earlier during surgery. Surprisingly, there was no evidence for the presence of mixed field agglutination. Subsequently transfused cells appeared to have lost $\mathrm{c}$ antigen as the patient was phenotyped CCee 6 days later. Antigen loss from antibody-coated RBCs has been described in patients with AIHA and HTR as well as in animal experiments [18-20]. Alternatively, c antigen became coated by patient's allo-anti-c, resulting in the antigen-blocked phenomenon. A third explanation might be that the transfused c-positive RBCs were destroyed.

In summary, although this case was rather complicated, further knowledge concerning the phenomena described here would be helpful in the management of such patients.

The remaining two major discussion points pertain firstly to the question whether or not masked alloantibodies would indeed cause massive HRT in patients with true AIHA, which is evidently relevant, since these patients already have a limited hemolytic capacity due to the ongoing hemolysis. Secondly, how anucleated cells are able to lose their antigen following reactions with corresponding antibodies, remains ambiguous.

\section{Disclosure Statement}

The authors declare no conflicts of interest. 


\section{References}

1 Beauregard P, Blajchman MA: Hemolytic and pseudohemolytic transfusion reactions: an overview of the hemolytic transfusion reactions and the clinical conditions that mimic them. Transfus Med Rev 1994;8:184199.

2 Petz LD, Garratty G: Immune Hemolytic Anemias, 2nd ed. Philadelphia, Churchill Livingstone, 2004.

3 Packman CH: Hemolytic anemia due to warm autoantibodies. Blood Rev 2008;22:17-31.

4 Salama A, Mueller-Eckhardt C: Delayed hemolytic transfusion reactions. Evidence for complement activation involving allogeneic and autologous red cells. Transfusion 1984;24:188-193.

5 Young PP, Uzieblo A, Trulock E, Lublin DM, Goodnough LT: Autoantibody formation after alloimmunization: are blood transfusions a risk factor for autoimmune hemolytic anemia? Transfusion 2004;44:6772.

6 Garratty G: Autoantibodies induced by blood transfusion. Transfusion 2004;44:5-9.

7 Salama A, Berghöfer H, Mueller-Eckhardt C: Red blood cell transfusion in warm-type autoimmune haemolytic anaemia. Lancet 1992;340:1515-1517.
Ahrens N, Pruss A, Kähne A, Kiesewetter H, Salama A: Coexistence of autoantibodies and alloantibodies to red blood cells due to blood transfusion. Transfusion 2007; 47:813-816.

9 Sulochana PV, Rajesh A, Mathai J, Sathyabhama S: Blocked D phenomenon, a rare condition with Rh D haemolytic disease of newborn - a case report. Int J Lab Hematol 2008;30:244-247.

10 Moiz B, Salman M, Kamran N, Shamsuddin N: Transfusion medicine illustrated: blocked D phenomenon. Transfusion 2008;48:1545-1546.

11 Lee E: Blocked D phenomenon. Blood Transfus 2013; 11:10-11.

12 Halverson GR, Tossas E, Velliquette RW, Lobo C, Reid ME, Frame T, Castilho L, Lee AH, Storry JR, Grodecka M, Waśniowska K, Duk M, Lisowska E: Murine monoclonal anti-s and other anti-glycophorin B antibodies resulting from immunizations with a GPB.s peptide. Transfusion 2009;49:485-494.

13 Lee E, Burgess G, Halverson GR, Huang TJ, Reid ME: Applications of murine and humanized chimaeric monoclonal antibodies for red cell phenotyping. $\mathrm{Br} \mathrm{J}$ Haematol 2004;126:277-281.
14 Lee E, Hart K, Burgess G, Halverson GR, Reid ME: Efficacy of murine monoclonal antibodies in RBC phenotyping of DAT-positive samples. Immunohematology 2006;22:161-165.

15 Wagner FF, Eicher NI, Jørgensen JR, Lonicer CB, Flegel WA: DNB: a partial D with anti-D frequent in Central Europe. Blood 2002;100:2253-2256.

16 Daniels G: Variants of RhD - current testing and clinical consequences. Br J Haematol 2013;161:461-470.

17 von Zabern I, Wagner FF, Moulds JM, Moulds JJ, Flegel WA: D category IV: a group of clinically relevant and phylogenetically diverse partial D. Transfusion 2013;53:2960-2973.

18 Zimring JC, Cadwell CM, Chadwick TE, Spitalnik SL, Schirmer DA, Wu T, Parkos CA, Hillyer CD: Nonhemolytic antigen loss from red blood cells requires cooperative binding of multiple antibodies recognizing different epitopes. Blood 2007;110:2201-2208.

19 Zimring JC, Cadwell CM, Spitalnik SL: Antigen loss from antibody-coated red blood cells. Transfus Med Rev 2009;23:189-204.

20 Powers A, Mohammed M, Uhl L, Haspel RL: Apparent nonhemolytic alloantibody-induced red-cell antigen loss from transfused erythrocytes. Blood 2007;109:4590. 